BMJ

Paediatrics

Open

\title{
Impact of the COVID-19 pandemic on radiology appointments in a tertiary children's hospital: a retrospective study
}

Dean Langan (D) , ${ }^{1,2}$ Susan Shelmerdine (D) , , ${ }^{1,2}$ Andrew Taylor, ${ }^{1,3}$ William A Bryant, ${ }^{2}$ John Booth, ${ }^{2}$ Neil J Sebire, ${ }^{1,2}$ Owen Arthurs, ${ }^{1,2}$ Mario Cortina-Borja ${ }^{1}$

\section{ABSTRACT}

In this retrospective observational study, we evaluated the impact of the COVID-19 pandemic in London on paediatric radiology activity, as a surrogate of overall hospital activity. We showed a large reduction in overall outpatient imaging activity: 49250 records occurred in the 371 days post COVID-19 period compared with an expected 67806 records pre COVID-19 period, representing 18556 'missed' records. Governmental restrictions were associated with reductions in activity, with the largest reduction in activity during tiers 3 and 4 restrictions. Rescheduling such missed outpatients' appointments represents considerable resource planning and the associated clinical impact on paediatric healthcare remains to be determined.

\section{INTRODUCTION}

The COVID-19 pandemic has been associated with significant changes in global and national health services provision, including through the impact of national lockdowns. ${ }^{1}$ Children are typically not directly severely affected by COVID-19 infection but may suffer as a result of missing standard healthcare. ${ }^{2}$ Several children's hospitals have seen a decrease in attendances for routine outpatient activity, some of which have been displaced online through virtual clinic appointments. ${ }^{3}$ The Royal College of Paediatric and Child Health ${ }^{4}$ found that approximately half of National Health Service trusts reported a decrease in their inpatient paediatric activity and loss of paediatric outpatient capacity was reported by $65 \%-84 \%$ of hospital trusts.

Percial re-use. See and permissions. Published by BMJ.

${ }^{1}$ UCL Great Ormond Street Institute of Child Health, London, WC1N 1EH, UK

${ }^{2}$ Great Ormond Street Hospital for Children NHS Foundation Trust, London, WC1N 3JH, UK ${ }^{3}$ UCL Institute of Cardiovascular Science, London, WC1N 1DZ, UK

Correspondence to Dr Dean Langan; d.langan@ ucl.ac.uk
Digital Research Environment (www.goshdrive.com). We categorised data into preCOVID and post-COVID (after and including Monday 23 March 2020, the start of the first national lockdown) and according to the UK government's official lockdown tiers $0-4$. We included all X-ray, fluoroscopy, ultrasound and echocardiography, CT scan, MRI, interventional radiology and nuclear medicine imaging studies. Negative binomial models were fitted to inpatient and outpatient daily records with covariates including pre/post COVID-19 covariates (binary), tiering system (tiers 0-4) and weekdays/holidays (binary).

\section{RESULTS}

Across the entire study period, 162135 patients were recorded generating a total of 191949 records, across 686 days (98 weeks), of which $315(45.9 \%)$ and $371(54.1 \%)$ days were 'pre-COVID-19' and 'post-COVID-19' respectively. Figure 1 shows these trends for daily records aggregated by week to smooth out reductions on weekends and holidays. The initial reduction in records was more pronounced for the first lockdown than for the second one despite the latter being confounded by the Christmas period. A total of 49250 records occurred in the 371 days post COVID-19 timeframe compared with an expected 67806 records pre COVID-19 timeframe, representing 18556 'missed' records. Expected weekday daily outpatient records reduced to 187.3 (95\% CI 177.8 to 197.3 ) post COVID-19 from 257.6 (95\% CI 243.5 to 272.4) pre COVID-19 (table 1), a reduction of $27.3 \%$ (95\% CI 21.5 to 32.6). A significant reduction is shown particularly under tiers 3 (151.5, 95\% CI 120.2 to 190.9$)$ and 4 (154.8, 95\% CI 143.6 to 169.9 ) government restrictions; these represent reductions of $41.2 \%$ (95\% CI 24.8 to 53.3 ) and $39.9 \%$ (95\% CI 34.1 to 45.2 ), respectively. Inpatient activity remained consistent with pre COVID-19 


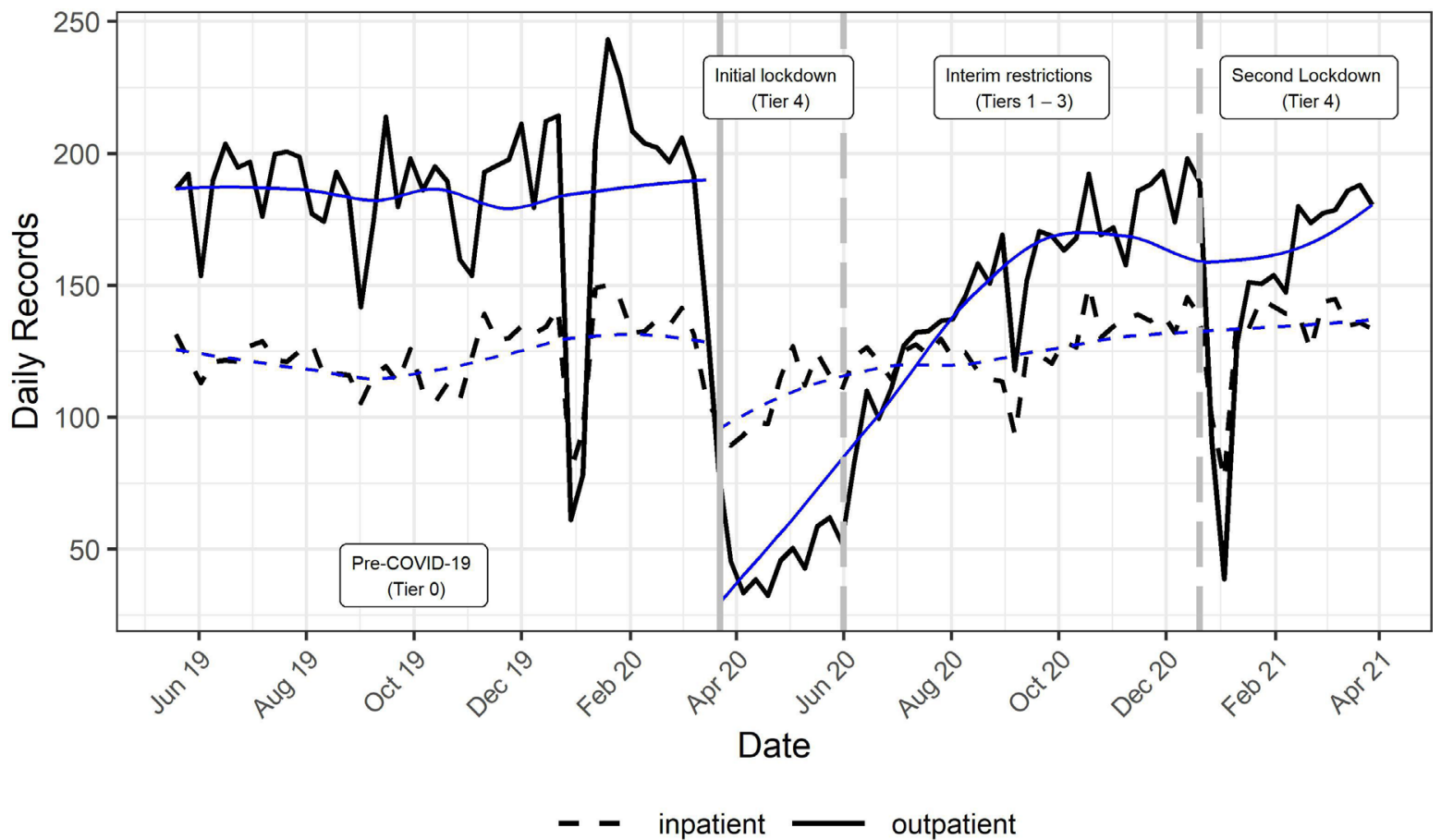

Figure 1 Time series of daily records (average per week), split by inpatients and outpatients. Black lines represent overall daily activity levels (averaged across each week). Blue lines show equivalent loess-smoothed lines of these same trends interrupted at the start of the first lockdown in March 2020. The graph is split into sections according to the government's lockdown tier system with pre COVID-19 (tier 0), partial restrictions (tiers 1-3) and full restrictions (tier 4) grouped together.

levels, with 46127 records post COVID-19 versus 45546 expected records assuming pre COVID-19 activity levels. There was a non-significant effect of full lockdown restrictions in weekday inpatient activity, with 157.0 (95\% CI 153.6 to 160.5 ) pre COVID-19 daily records and 152.2 (95\% CI 147.7 to 157.0 ) daily records under tier 4 restrictions (table 1).

table 1 table 1

\section{DISCUSSION}

We have demonstrated that the COVID-19 period was associated with a reduction in radiological outpatient activity. Several factors could be responsible, including parental anxiety related to travelling during a lockdown, perceived wellness in their children, a possible increase in mental health issues or difficulty coping with routine tasks. ${ }^{5}$

Table 1 Overall daily records (with $95 \% \mathrm{Cl}$ ) from negative binomial models split by inpatients and outpatients, pre and post COVID-19 and tiering system

\begin{tabular}{|c|c|c|c|c|}
\hline & \multicolumn{2}{|l|}{ Inpatients } & \multicolumn{2}{|l|}{ Outpatients } \\
\hline & Weekday & Holiday & Weekday & Holiday \\
\hline Pre COVID-19 & 157 (153.5 to 160.5$)$ & 44.6 (42.7 to 46.5$)$ & 257.6 (243.5 to 272.4$)$ & $\begin{array}{l}11.9 \text { (10.7 to } \\
13.2)\end{array}$ \\
\hline Post COVID-19 (overall) & 155.4 (152.3 to 158.7$)$ & 53.4 (51.4 to 55.4$)$ & $187.3(177.8$ to 197.3$)$ & $8.2(7.4$ to 9.1$)$ \\
\hline Lockdown tier 0 & 157 (153.6 to 160.5$)$ & 44.6 (42.7 to 46.5$)$ & 257.6 (244.1 to 271.7$)$ & $\begin{array}{l}11.9 \text { (10.8 to } \\
13.1)\end{array}$ \\
\hline Lockdown tier 1 & 153.8 (148 to 159.8 ) & 46.7 (43.5 to 50.3 ) & 213.6 (194.6 to 234.5 ) & 7.5 (6.2 to 9$)$ \\
\hline Lockdown tier 2 & 164.2 (157.4 to 171.3$)$ & 54.1 (49.9 to 58.7 ) & 224.7 (202.6 to 249.3 ) & 9.3 (7.5 to 11.5$)$ \\
\hline Lockdown tier 3 & 152.9 (139.2 to 168$)$ & 62.2 (51.5 to 75.2 ) & 151.5 (120.2 to 190.9$)$ & 9.5 (5.7 to 15.7$)$ \\
\hline Lockdown tier 4 & $152.2(147.7$ to 157$)$ & 56.1 (53.3 to 59.1 ) & 154.8 (143.6 to 166.9$)$ & 8.1 (7 to 9.3$)$ \\
\hline
\end{tabular}

Post COVID-19 dates were defined as all dates after and including Monday 23 March 2020, when the first national lockdown came into force in the UK. Post COVID-19 dates were further subcategorised according to the UK government's official lockdown tiering system (tiers $0-4$, based on local tiering allocation in London with tier 4 being the most stringent form of lockdown). Although the tiering system was announced in October 2020, we retrospectively categorised all post- COVID-19 restrictions in London prior to October 2020 according to the same system as follows: tier 4 from the 23 March 2020; on 1 June 2020, lockdown restrictions eased with primary schools reopening (tier 3); on 14 June 2020, non-essential shops reopened (tier 2) and on 4 July 2020, other businesses reopened such as pubs and restaurants (tier $1)^{6}$ 
Assuming a $10 \%$ increase in working activity above normal pre COVID-19 levels, 720 weekdays (2.75 years) would be required to catch-up on all outpatient activity. This is not necessarily desirable, as there may have been inefficiencies in existing referral patterns and we did not evaluate the urgency of individual examinations, but further analysis of this data will identify which activities should be prioritised or postponed. The main limitation of this study was its retrospective nature from a single-specialist children's centre, which may not be generalisable. We did not collect data on staffing levels or on parental experience directly, and so the detailed mechanisms through which hospital activity reduced remain undetermined. Equally, the effect on paediatric healthcare caused by these missed appointments is yet to be quantified.

Contributors DL was responsible for the content and acts as a guarantor. NJS, $O A$ and $A T$ contributed equally to the initial conception and design of the work. $\mathrm{DL}$ and MC-B contributed to the analysis and interpretation of data. SS, OA and NJS contributed to the literature search and put findings in the context of existing evidence. JB and WAB provided the dataset available via the Digital Research Environment platform. DL, SS, NJS, OA and MC-B contributed to writing the initial draft of the manuscript, with all other authors contributing to the final version. $\mathrm{OA}$ and MC-B contributed as last authors.

Funding This research was supported by the National Institute for Health Research (NIHR) Great Ormond Street Hospital (GOSH) Biomedical Research Centre. This article presents independent research funded by the Medical Research Council (MRC) (Grant Ref: MR/R00218/1), The Royal College of Radiologists (RCR) and NIHR (NIHR-CS-012-002). The GOSH Digital Research Environment is part funded by the GOSH Children's Charity. The views expressed are those of the authors and not necessarily those of the National Health Service, the NIHR or the UK Department of Health.

Disclaimer The funding bodies were neither involved in study design, data collection, analysis and interpretation nor in the decision to submit the manuscript for publication.
Competing interests None declared.

Patient and public involvement Patients and/or the public were not involved in the design, or conduct, or reporting, or dissemination plans of this research.

Patient consent for publication Not required.

Ethics approval Ethical approval for this study was granted as part of a larger approval for use of routinely collected non-identifiable data (REC approval: $17 /$ L0/0008).

Provenance and peer review Not commissioned; externally peer reviewed.

Open access This is an open access article distributed in accordance with the Creative Commons Attribution Non Commercial (CC BY-NC 4.0) license, which permits others to distribute, remix, adapt, build upon this work non-commercially, and license their derivative works on different terms, provided the original work is properly cited, appropriate credit is given, any changes made indicated, and the use is non-commercial. See: http://creativecommons.org/licenses/by-nc/4.0/.

ORCID iDs

Dean Langan http://orcid.org/0000-0002-5414-8882

Susan Shelmerdine http://orcid.org/0000-0001-6642-9967

\section{REFERENCES}

1 Moynihan R, Sanders S, Michaleff ZA, et al. Impact of COVID-19 pandemic on utilisation of healthcare services: a systematic review. BMJ Open 2021;11:e045343.

2 Issitt RW, Booth J, Bryant WA, et al. Children with COVID-19 at a specialist centre: initial experience and outcome. Lancet Child Adolesc Health 2020:4:e30-1.

3 Fung A, Irvine M, Ayub A, et al. Evaluation of telephone and virtual visits for routine pediatric diabetes care during the COVID-19 pandemic. J Clin Transl Endocrinol 2020;22:100238.

4 Royal College of Paediatric and Child Health RWT. The impact of COVID-19 on child health services - report, 2020. Available: https:// www.rcpch.ac.uk/sites/default/files/managed-pdf/Impact\%20-ofCOVID-19-child-health-services-web.pdf.pdf [Accessed 7 Apr 2021].

5 Patrick SW, Henkhaus LE, Zickafoose JS, et al. Well-Being of parents and children during the COVID-19 pandemic: a national survey. Pediatrics 2020;146:e2020016824.

6 Analysis IfG. Timeline of UK coronavirus lockdowns, March 2020 to March 2021. Available: https://www.instituteforgovernment.org. uk/sites/default/files/timeline-lockdown-web.pdf [Accessed 30 Mar 2021]. 